\title{
A (NOVA) POLÍTICA DE FORMAÇÃO DE PROFESSORES: A PRIORIDADE POSTERGADA
}

\author{
Helena Costa Lopes de Freitas ${ }^{*}$ \\ É criminoso o divórcio entre a educação que se recebe em \\ uma época e a época. (José Martí)
}

\begin{abstract}
RESUMO: O texto examina as políticas e programas no campo da formação do atual governo, identificando linhas de uma política marcada por ações de formação focalizadas, de cursos a distância, pela Universidade Aberta do Brasil. Analisa suas relaçōes com a transformação da Coordenação de Aperfeiçoamento de Pessoal de Nível Superior (CAPES) em agência reguladora da formação de professores. Tomando por referência a base comum nacional, indica as condiçóes para uma política global de formação e profissionalização dos profissionais da educação, nos termos defendidos pela área da educação e pela Associação Nacional pela Formação dos Profissionais da Educação (ANFOPE).
\end{abstract}

Palavras-chave: Formação de professores. Política nacional de formação. Universidade Aberta do Brasil. Educação a distância.

THE NEW TEACHER'S TRAINING POLICY: THE DEFERRED PRIORITY

ABSTRACT: This text explores the present government policies and programs in the field of training and identifies political lines marked by actions of focalized training, through distance courses, and by the Open University of Brazil. It analyses its relations to the transformation of the Coordination for the Advance of Graduate Personnel (CAPES) into an agency that regulates teachers' training. Based on the Brazilian common basis, it points out conditions for a global policy to train and professionalize the professionals of education in

Professora aposentada da Faculdade de Educação da Universidade Estadual de Campinas (UnICAmP) e presidente da Associação Nacional pela Formação dos Profissionais da Educação (ANFOPE).E-mail: helena.freitas@uol.com.br

Educ. Soc., Campinas, vol. 28, n. 100 - Especial, p. 1203-1230, out. 2007 
the terms advocated by the field of education and by the National Association for the Professional Educators Formation (ANFOPE).

Key words: Teachers' training. Brazilian training policy. Open university of Brazil. Distance education.

\section{A situação atual da formação}

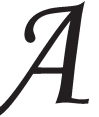

necessidade de uma política global de formação e valorização dos profissionais da educação que contemple de forma articulada e prioritária a formação inicial, formação continuada e condições de trabalho, salários e carreira, com a concepção sócio-histórica do educador a orientá-la, faz parte das utopias e do ideário de todos os educadores e das lutas pela educação pública nos últimos 30 anos. Contudo, sua realização não se materializa no seio de uma sociedade marcada pela desigualdade e pela exclusão próprias do capitalismo. Entender estas amarras sociais é importante para que não criemos ilusões de soluções fáceis para os problemas da educação e da formação. As condições perversas que historicamente vêm degradando e desvalorizando a educação e a profissão docente se mantêm em nosso país, em níveis bastante elevados. A má qualidade da formação e a ausência de condições adequadas de exercício do trabalho dos educadores se desenvolvem há décadas, em nosso país, e em toda a América Latina, de forma combinada, impactando na qualidade da educação pública, em decorrência da queda do investimento público e da deterioração das condições de trabalho dos educadores e trabalhadores da educação (Internacional da Educação, 2007).

Quanto ao financiamento, a redução dos investimentos públicos na educação, ao longo dos últimos anos de políticas neoliberalizantes, persiste e se expressa no orçamento para a educação, para este ano, estimado em 4,3\% do PIB, ${ }^{1}$ contrastando vergonhosamente com dados que indicam que, no período de quase duas décadas, o setor público tem transferido de $4 \%$ a $7 \%$ do PIB por ano ao setor bancário, na forma de pagamento de juros (Pochmann, 2007). ${ }^{2}$

No que diz respeito às condiçôes de trabalho, salários e carreira, não há política para seu enfrentamento e superação, em especial as metas do Plano Nacional de Educação (PNE) quanto à implementação gradativa da escola integral, a diminuição do número de crianças por 
sala de aula no ensino fundamental, o cumprimento da relação adulto-criança nos espaços de educação infantil, a implementação do piso salarial nacional, a implantação gradativa da jornada única, com a concentração do professor em apenas uma escola, e jornada compatível com as responsabilidades e os desafios que a sociedade e as necessidades de formação humana lhe colocam. As diretrizes para a carreira, normatizadas pelo Conselho Nacional de Educação desde 1997 (Resolução CNE/CEB n. 03/97), tampouco conseguem ser materializadas nas políticas municipais e estaduais em planos de cargos e carreiras que poucos municípios possuem. Falamos, portanto, de uma política de valorização do magistério como profissão, com o sentido de projeto de vida e futuro, enquanto percurso da existência, uma carreira que deve necessariamente estruturar-se tendo como parâmetro orientador o compromisso social dos educadores com as necessidades educativas de nosso povo e com a qualidade histórica da escola.

As condições do trabalho pedagógico na escola pública, impactadas pela produção da vida material de nossa infância e juventude, já denunciadas pela Confederação Nacional dos Trabalhadores em Educação (CNTE) em seus documentos Retrato da Escola ${ }^{3}$ demandam investimento público massivo em políticas de profissionalização e formação continuada de professores, de qualidade elevada, para a educação básica, além de condições de infra-estrutura que ofereçam suporte para a produção de conhecimento e a formação científica adequada às demandas contemporâneas da ciência e da técnica, da cultura e do trabalho.

São estas as condições que afastam do magistério amplas parcelas da juventude que, desde as universidades e no ensino médio normal, poderiam incorporar-se aos processos de formação das novas gerações. As políticas de formação têm colocado perspectivas diferenciadas de profissionalização e aprimoramento para cada um destes espaços, ao invés de condiçôes igualitárias. O grande número de estudantes que escolhem ainda hoje a licenciatura, nas instituições de ensino superior (IES), evidencia as potencialidades da juventude na direção da profissão. No entanto, as licenciaturas e a formação de professores não se constituem prioridade nos investimentos e recursos orçamentários. Há apenas um programa, além das bolsas estudantis, destinado às universidades públicas, o Pró-docência, ${ }^{4}$ no âmbito da Secretaria de Ensino Superior (SESu), programa específico e datado, que tem como objetivo 
A (nova) política de formação de professores: a prioridade postergada

"promover o desenvolvimento de novas metodologias de ensino, acompanhamento e avaliação dos diferentes cursos de licenciatura" (Brasil, 2007a). No entanto, o montante de recursos a ele destinados, ${ }^{5} 3 \mathrm{mi}$ lhôes de reais, é insignificante, diante dos valores destinados a outros programas $^{6}$ no âmbito da formação.

A ação do Estado nas políticas de formação, em resposta aos desafios enfrentados pela juventude, vem se caracterizando pela fragmentação, assegurando, conseqüentemente, dimensões diferenciadas de profissionalização com aprimoramento em cada um desses espaços, diferenciando os conhecimentos científicos, técnicos e culturais oferecidos. Aos estudantes de licenciaturas, oriundos da escola pública, são concedidas bolsas PROUNI, em instituições privadas, em cursos de qualidade nem sempre desejável, ou programas de formação nos pólos municipais da Universidade Aberta do Brasil (UAB), intensificando o reforço às IES privadas, em detrimento do acolhimento massivo da juventude nas licenciaturas das instituições públicas. Nestas, instituições de ensino e pesquisa, a Bolsa Docência/CAPES espera pelos estudantes que logram vencer seus processos seletivos, visando inseri-los nas áreas de educação básica com maior carência de "professores e em escolas públicas onde os índices de desenvolvimento da educação básica (IDEBs) estão abaixo da média nacional, 3.8" (Brasil, 2007).

Estas iniciativas ocultam a desigualdade entre instituições de ensino e instituições de pesquisa, estudantes que estudam e pesquisam e estudantes que trabalham, produzindo a desigualdade educacional.

No ensino médio normal, a pressão da juventude pela profissionalização após o fundamental coloca imenso contingente de jovens - em torno de $450 \mathrm{mil}^{7}$ em todo o país -, teoricamente, no exercício do magistério, na perspectiva de profissionalização. A formação superior, para a grande maioria, se dará nas instituições privadas, como bolsistas, ou nos cursos a distância, em pólos da UAB, nos cursos de pedagogia e cursos normais superiores, concomitante ao trabalho na educação básica.

Está em curso uma política de formação de professores que oferece diferentes oportunidades de formação aos estudantes, dependendo dos percursos anteriores na educação básica e das suas condiçôes de classe, dissimulada, sob a concepção de eqüidade, de que ao Estado cabe oferecer igualdade de oportunidades, em contraposição à igualdade de condiçôes, que se efetivaria pelo desenvolvimento da formação exclu- 
sivamente nas universidades, como projeto institucional, onde suas faculdades e centros de educação, articulados aos institutos, se constituem lócus privilegiado para a formação de qualidade elevada de todos os educadores.

A "escassez" de professores para a educação básica, apontada pelo relatório do CNE, apresentado em sua reunião de julho de 2007 , não pode, portanto, ser caracterizada como um problema conjuntural e nem mesmo exclusivamente emergencial. Ao contrário, é estrutural, um problema crônico, ${ }^{8}$ produzido historicamente pela retirada da responsabilidade do Estado pela manutenção da educação pública de qualidade e da formação de seus educadores. As alternativas - conjunturais - que vêm sendo apontadas para o enfrentamento deste grave problema - a complementação pedagógica em licenciaturas paralelas de 540 horas ou "aceleradas" de 120 horas aos bacharéis de qualquer área9 e as bolsas aos 150 mil estudantes de pós-graduação ${ }^{10}$ para atuarem como docentes de escolas públicas, após passarem por "treinamento" - não equacionarão a escassez na direção de uma política de valorização da formação dos professores. Pelo contrário, aprofundarão o quadro de sua desprofissionalização pela flexibilização e aligeiramento da formação.

Evidencia-se, portanto, um divórcio entre as necessidades atuais da escola e de profissionalização da juventude e um sistema educacional que não oferece as possibilidades que habilite os jovens, de forma plena, para fazer frente à vida do trabalho concreto na escola pública.

Apesar da vasta produção de conhecimento na área sobre os dilemas, desafios, perspectivas e limites, produzida no campo da formação de professores, que se esperava pudesse ser apropriada pelas políticas públicas no governo Lula, no período 2002-2005, o que estamos vivenciando é o embate entre as demandas das entidades e dos movimentos e as ações do governo em continuidade às políticas neoliberais do período anterior, e uma enorme retração na participação dos movimentos na definição da política educacional.

As soluções dos problemas relativos à formação dos professores não estão vinculadas a questões técnicas, nem sequer a grandes proposições teóricas. Elas se articulam com a possível e devida apropriação, pelo Estado, dos resultados dos estudos dos pesquisadores que têm orientado os educadores, seus movimentos e entidades no debate sobre os princípios e os fundamentos da formação. 
Este artigo se propõe a examinar as políticas recentes para a formação dos profissionais da educação. Analisa as ações atuais do novo governo para o período de 2006-2010, o fortalecimento da Universidade Aberta do Brasil e a nova CAPES como agência reguladora da formação de professores.

\section{As políticas de formação}

\section{A política (sempre emergencial) da formação focalizada}

A configuração da formação de professores em nosso país respondeu ao modelo de expansão do ensino superior implementado na década de 1990, no âmbito das reformas do Estado e subordinado às recomendações dos organismos internacionais. ${ }^{11}$ No âmbito da formação, caracteriza-se pela criação dos Institutos Superiores de Educação e pela diversificação e flexibilização da oferta dos cursos de formação - normais superiores, pedagogia, licenciaturas, cursos especiais e cursos à distância -, de modo a atender a crescente demanda pela formação superior.

A expansão desenfreada dos Cursos Normais Superiores e Pedagogia, ${ }^{12}$ além de cursos de licenciaturas, desenvolveu-se principalmente em instituições privadas sem compromisso com a formação em quaisquer de seus níveis e modalidades. Agregue-se a essa condição a existência de centenas de Cursos de EAD, em mais de 50 instituições privadas, que se expandem nos mais diversos pólos pelo interior dos estados, imprimindo uma condição desigual nos processos de formação de professores. Destaca-se, nesse quadro, a situação dos Cursos de Pedagogia', divididos hoje em mais de 60 modalidades de bacharelados e "habilitaçôes", sem qualquer compromisso com o desenvolvimento da educação básica, em decorrência das confusas idas e vindas oriundas das regulamentaçôes do período (Campos, 2004)

A retomada e expansão de cursos normais em nível médio, para a formação de professores para a educação infantil e séries iniciais do ensino fundamental, consolidam a formação neste nível de ensino como política pública permanente, não transitória. Com isso, posterga-se a formação superior destes professores nas universidades, aspiração histórica dos educadores e exigência para a elevação da qualidade da educação pública. A manutenção da formação em nível médio se constitui, 
nas condições atuais, um dos principais pilares para a continuidade e consolidação da política de formação superior de professores em serviço, informada pela noção de competências, cumprindo fielmente um dos postulados da reforma no campo da formação, no sentido de que "aos professores em exercício na educação básica que não tenham estudos superiores, deverá ser dada oportunidade de realizá-los, garantindo melhor domínio dos conteúdos a serem lecionados e constituição das competências pedagógicas para promover a aprendizagem dos mesmos" (PREAL, 2002, grifos nossos).

A forma adotada pelos sistemas de ensino, desde 2000, para a formação superior dos professores em exercício na educação básica, responde, como indicamos em 2003 (Freitas, 2003), à recomendação dos organismos internacionais para a formação de professores, como forma de atender massivamente à demanda emergente por formação, com custos reduzidos. Introduz os tutores, mediadores da formação, supervisionados por docentes universitários, alterando radicalmente a concepção e o caráter do trabalho docente no ensino superior. A iniciativa de localizar os pólos presenciais em vários municípios, com a presença circunstancial ${ }^{13}$ dos estudantes, representou novas formas de organização da formação, mediante concessão de bolsas a professores das próprias redes de educação básica ${ }^{14}$ ou a pós-graduandos, para atuarem como tutores, e se desenvolveu, no período de 2003-2006, em continuidade à política adotada para a formação continuada de professores. Este modelo, desenvolvido à distância através de mídias interativas e novas tecnologias da informação e comunicação, se organiza em projetos de cursos que partem do trabalho dos professores, exclusivamente em sua dimensão prática, reduzindo as possibilidades da mediação pedagógica necessária no processo de ensino, e não se sustenta quando confrontado com as condições de produção da vida material e da organização da escola e da educação, que demandam outras habilidades, capacidades e competências de seus educadores. Estudos recentes (Araújo, 2007; Chueire, 2005), analisam experiências de formação desenvolvidas por universidades, em cursos com estas características, e apontam suas potencialidades e limites na ascensão a processos mais elevados de formação humana e profissionalização. Este ainda é um campo em desenvolvimento na área da educação.

Assim, as açôes do MEC têm se pautado pela continuidade de programas de caráter continuado e compensatório, destinados à formação de 
A (nova) política de formação de professores: a prioridade postergada

professores leigos, em exercício a distância, em cooperação com os sistemas de ensino. Situam-se, nessa perspectiva, os programas vinculados à Rede Nacional de Formação Continuada de Professores, na qual se inserem os Centros de Pesquisa e Desenvolvimento da Educação, criados em 2003:15 o Pró-Formação, no âmbito da Secretaria de Educação a Distância (SEED), iniciado em 1997 e finalizado em 2004, direcionado à formação em nível médio dos professores de $1^{\mathrm{a}}$ a $4^{\mathrm{a}}$ séries do ensino fundamental; o Pró-Infantil, ${ }^{16}$ iniciado em 2005, dirigido à formação em nível médio dos professores de educação infantil, centrado na formação por tutorias exercidas pelos professores da rede e supervisionadas pelas IES participantes. O Pró-Letramento, no âmbito da Secretaria de Educação Básica (SEB), desenvolvido em parceria com os sistemas de ensino e com as universidades da Rede de Formação Continuada e Desenvolvimento da Educação, constitui-se o único programa de formação continuada de professores das séries iniciais do ensino fundamental centrado em alfabetização e matemática.

\section{O Pró-Licenciatura, a UAB e a CAPES}

A institucionalização da formação superior em programas de educação a distância, na concepção de formação continuada, aliada à utilização de novas tecnologias, é hoje o centro da política de formação em serviço. A criação do Programa Pró-licenciatura, em 2005, e da Universidade Aberta do Brasil (UAB), pelo Decreto n. 5.800/06, em 2006, institucionaliza os programas de formação de professores a distância como política pública de formação.

O Sistema UAB foi criado com o objetivo de expandir e interiorizar a oferta de cursos e programas de educação superior públicos, a distância, oferecendo, prioritariamente, cursos de licenciatura e de formação inicial e continuada de professores da educação básica, cursos superiores para capacitação de dirigentes, gestores e trabalhadores em educação básica (Decreto n. 5.800/06). A oferta de cursos e programas de educação superior a distância por instituições públicas de ensino superior, em articulação com pólos de apoio presencial, nos municípios, representa, sem dúvida, ruptura com os programas de formação a distância, de curta duração, de caráter mercadológico, que perduraram até pouco tempo em nosso país. Esta iniciativa, no entanto, tem suas contradiçōes, na medida em que privilegia a modalidade de educação à distância para a formação inicial de professores em exercício. 
Sua priorização vem se desenvolvendo em detrimento do reforço massivo às licenciaturas nas universidades e demais IES, envolvidas em processos de reformulação dos cursos de licenciaturas desde a aprovação das Diretrizes Curriculares para Formação de Professores, em 2002, e dos cursos de Pedagogia, em 2006. No contexto em que foram produzidas, de grandes embates sobre as políticas de formação de professores dos anos FHC, as diretrizes provocaram movimentos diferenciados, contraditórios, no desenvolvimento e materialização da organização curricular em cada IES, dependendo das concepçôes norteadoras dos currículos e da história e trajetória das relações entre as áreas específicas da licenciatura e as faculdades/centros e departamentos de educação. Em várias universidades, os centros de educação e, portanto, os estudos do campo da educação e os estudos pedagógicos foram alijados da responsabilidade pela formação dos professores, rebaixando as exigências do campo da teoria pedagógica na organização curricular. Tais procedimentos, permitidos pelo conteúdo das diretrizes, em relação à carga horária e o tempo de duração, ao espaço destinado aos estudos do campo da educação, diluídos nas horas destinadas aos conteúdos científicos culturais e a concepção de práticas e estágios supervisionados, que descaracteriza o ensino como atividade essencial, vão se revelando como um rebaixamento na qualidade da formação teórica, no campo das Ciências da Educação, mas também no campo das áreas específicas, na medi$\mathrm{da}$ em que apresentam uma nova concepção de ensino que tende a secundarizar o conhecimento teórico e sua mediação pedagógica, como analisam Dias e Lopes (2003).

Expressão deste movimento de secundarização do conhecimento teórico do campo epistemológico da educação e sua mediação pedagógica, em níveis mais elevados e não tão sutis, é a nova configuração que vem se dando à pós-graduação da área, a partir de 2000, com a criação dos cursos de pós-graduação em ensino de ciências e matemática, na área multidisciplinar, separados da área de educação na CAPES, com a abertura de mestrados profissionais na área da formação de professores, separados dos mestrados acadêmicos da área da educação.

A redução do espaço dos fundamentos epistemológicos e científicos da educação nos processos formativos, e a prevalência de uma concepção conteudista e pragmática de formação de professores, ancoradas na epistemologia da prática e na lógica das competências, vem produzindo novas proposiçôes para as licenciaturas que se desenvolvem no 
interior dos programas de educação à distância. É nesse contexto que se insere a criação do programa Pró-Licenciatura, ${ }^{17}$ em 2005, no âmbito da SEB, consolidando, como política pública, esse movimento de retirada das universidades e dos centros e faculdades de educação dos processos de concepção e formulação das políticas e programas de formação de professores. De responsabilidade partilhada com a SEED, desenvolve-se em parceria com os sistemas de ensino e IES, públicas ou comunitárias. A Proposta Conceitual e Metodológica (SEB/SEED/MEC, 2007) aproxima-se da concepção de formação continuada, organiza-se a partir do trabalho pedagógico dos professores, na escola pública, e com uma clara determinação quanto ao formato do curso - obrigatoriamente em cursos de licenciatura na modalidade de Educação a Distância (EAD), de forma a permitir que o professor-aluno mantenha suas atividades docentes (SEB/SEED/MEC, 2007). Ou seja, uma indução às universidades para a formação a distância, aos sistemas, permitindo a contratação de professores em nível médio, e aos professores, a continuidade no trabalho como condição para a formação superior. É concebido pela SEB/MEC e SEED, no lugar da Secretaria de Ensino Superior, a quem caberia estabelecer os parâmetros para os processos de fortalecimento dos cursos de licenciaturas, como formação de base, de caráter científico-acadêmico a ser desenvolvido nas instituições de ensino superior. $\mathrm{O}$ papel das IES, neste contexto, tem se limitado a uma associação, em parceria, para o desenvolvimento dos cursos. Nestas parcerias, não estão previstas as responsabilidades das faculdades e centros de educação, como intrínsecas ao projeto pedagógico de formação, exceção feita aos seus cursos de pedagogia.

Nesse contexto, as universidades perdem sua autonomia didático-científica quanto à definição do caráter e da concepção do projeto, pois não têm participação na elaboração das Propostas Conceituais e Metodológicas do Programa. Assim entendido, os objetivos e os conteúdos das licenciaturas, a serem oferecidos pelas instituiçóes de ensino superior, passarão a ser definidos fora delas, ${ }^{18}$ tendo como referência os objetivos de formação da educação básica, centrados exclusivamente nos processos de aprendizagem dos conteúdos escolares, na avaliação e gestão do trabalho e da formação. A sólida formação teórica de base, científica, nos fundamentos das Ciências da Educação e nas teorias pedagógicas, encontra-se comprometida, pela retirada desses estudos dos cursos de formação, como analisamos anteriormente, neste artigo. A ênfase nos 
conteúdos de ensino prevalece e se aprofunda pelo caráter pragmático que impregna a Proposta Conceitual e Metodológica do Programa, cabendo às IES proporem a estrutura operacional e a estrutura curricular, envolvendo a formação dos tutores e a elaboração do material didático, à luz das concepções elaboradas pela SEB/MEC.

O Programa se propõe, como objetivo final, a impulsionar mudanças efetivas à melhoria da educação básica, combatendo diretamente a deficiência de qualidade da escolarização, detectada pelo SAEB. Suas proposições e conteúdo constituem-se instrumento central no processo de regulação da formação, adequando-a aos processos de avaliação da educação básica que tem no Índice de Desenvolvimento da Educação Básica - IDEB (Brasil, 2007b) - seu principal instrumento regulador.

Esta nova configuração da formação inicial deve ser analisada tendo como referência a crítica à concepção de educação e de formação que informa os cursos e programas de EAD, na medida em que se impõe por ações "minimalistas" na formação, pelos encontros presenciais de 4 horas semanais, pelo caráter da ação dos tutores, uma forma precarizada de trabalho de formação superior, e ainda quanto aos processos de elaboração dos materiais didáticos, financiamento e instrumentos necessários à formação superior. $\mathrm{O}$ caráter das propostas atuais de cursos a distância, nos quais os encontros presenciais acontecem apenas uma vez por semana, em caráter não obrigatório, sendo apenas a avaliação obrigatoriamente presencial, está em sintonia com o sentido de responsabilização que se imprime às políticas atuais. Responsabiliza-se os estudantes, que já chegam a estes cursos em condições desiguais frente aos demais estudantes das universidades, sem que se ofereça, pelas condições de ensino - a mediação dos tutores e a ênfase em estudos individualizados e solitários -, possibilidades de auto-superação de suas limitações, resultantes de seu percurso na educação básica.

A ANFOPE tem assumido uma posição clara em defesa da apropriação dos recursos tecnológicos contemporâneos, tanto na formação inicial quanto nos programas de formação continuada, por considerar que as novas tecnologias não se constituem em propriedade privada de nenhum segmento, ao contrário, pertencem ao conjunto da sociedade e são meios, instrumentos e mecanismos para ampliação da vivência democrática. Lidar com as novas linguagens e compreender as novas formas do trabalho material é um desafio que está posto para todos os educadores. A tecnologia é uma realidade que impregna nossas vidas e 
A (nova) política de formação de professores: a prioridade postergada

a escola se defronta com o desafio de um trabalho pedagógico voltado para as habilidades necessárias ao entendimento dessas novas relações. A tecnologia não pode ser vista, entretanto, como um valor em si mesmo, mas como o sentido de totalidade do homem e de uma educação sustentada na realidade (ANFOPE, 1998).

A maioria dos cursos de formação na modalidade a distância, no Brasil, contraria todos esses requisitos e se apresenta como uma forma de aligeirar e baratear a formação. Por isso mesmo, tende a ser pensada mais como uma política compensatória, que visa a suprir a ausência de oferta de cursos regulares a uma determinada clientela, sendo dirigida a segmentos populacionais historicamente já afastados da rede pública de educação superior. $\mathrm{O}$ abandono elevado que se observa nesses cursos e mesmo os resultados dos processos avaliativos passam a ser encarados como uma responsabilidade individual dos estudantes, ocultando a exclusão provocada pela desigualdade educacional.

É por estas vias que vão se produzindo e reproduzindo as desigualdades na formação de professores, que persistem em nosso país há muitas décadas. A necessidade de expansão da escolarização, o reduzido investimento público na educação e a impossibilidade do Estado - mínimo prover os recursos necessários que garantam a expansão massiva da educação superior pública - universitária, presencial - e a formação de qualidade elevada para todos os professores alteram significativamente o caráter da formação em nosso país. As iniciativas atuais de massificação, por intermédio da UAB, cumprem as metas estatísticas e conformam os professores a uma concepção de caráter subordinado, meramente instrumental, em contraposição à concepção de educador de caráter sócio-histórico, dos professores como profissionais da educação, intelectuais essenciais para a construção de um projeto social emancipador que ofereça novas possibilidades à educação da infância e da juventude.

Vivenciamos a luta da juventude e dos professores pela formação e a incorporação a processos que elevem a qualidade da educação básica, em contraposição a um sistema educacional discriminatório e injusto, que segue negando a esta mesma juventude e à grande maioria da população o acesso à educação, discriminando-os na qualidade dos conhecimentos que oferece.

Nesse contexto, já não é suficiente anunciar a necessidade de uma política global de formação e valorização do magistério, que, no quadro 
atual, se impõe com referenciais e parâmetros de sentidos contraditórios para as diferentes modalidades de formação, seja presencial ou à distância.

Observa-se, portanto, no desenvolvimento de políticas de formação implementadas nos últimos anos, a produção das condições para que se institua uma nova regulação da formação, "mais flexível na definição dos processos e rígida na avaliação da eficiência e eficácia dos resultados" (Barroso, 2005, p. 727), cuja qualidade certamente estará determinada, nos próximos anos, unicamente pela "evolução" dos resultados das escolas, segundo os índices de desenvolvimento da educação básica, o IDEB (PNE, 2007).

\section{A nova CAPES e a regulação da formação}

Uma das características essenciais no quadro que se desenha a partir da redefinição do papel do estado, originário das mudanças ocorridas no âmbito do capitalismo, é a necessidade de regulação, que adquire caráter central no campo da educação e da formação de professores. É este caráter do estado, regulador, que orienta as diferentes políticas e suas medidas de implementação, buscando responder a questões como: quais os conhecimentos necessários a todas as crianças e jovens, como desenvolver a aprendizagem desses conhecimentos, como preparar os professores para essa tarefa (Diretrizes e Referenciais), quais as instituições mais adequadas e sua forma institucional e pedagógica (regulamentação das instituições formadoras). Por último, como avaliar os sujeitos envolvidos nas tarefas educativas exigidas pelas reformas (sistemas de avaliação de estudantes - SAEB, ENEM, Prova Brasil) e como controlar o trabalho docente e a produção da formação - em processos de acreditação de cursos e instituições e de certificação de professores, que pode retornar nas políticas atuais.

O trabalho docente, nessa perspectiva, deve necessariamente ser reduzido à prática individual, às suas dimensôes técnicas, de modo a poder ser avaliado, mensurado e certificado, visando adaptar os professores, a escola e seus processos formativos às transformações necessárias no âmbito das reformas propostas. Este processo de regulação do trabalho, na concepção (re) configurada de competências, restrita as habilidades, atitudes, modelos didáticos e capacidades dos professores, vem orientando as diferentes ações no campo da formação, circunscri- 
A (nova) política de formação de professores: a prioridade postergada

to às diretrizes, referenciais e parâmetros para a educação e a formação de seus professores. No entanto, novas formas de regulação encontramse latentes desde 2003, e retornam agora, diante da centralidade da avaliação da qualidade da educação básica, reafirmada no Plano de Desenvolvimento da Educação, e para a qual concorre significativamente a formação dos professores.

A nova configuração que se desenha para a formação de professores articula a CAPES à expansão da UAB e ao Programa de Apoio a Planos de Reestruturação e Expansão das Universidades Federais (REUNI) (Decreto n. 6.096/07). Como agência reguladora da formação, a CAPES terá como finalidade "induzir e fomentar, inclusive em regime de colaboração com os Estados, os municípios e o Distrito Federal e exclusivamente mediante convênios com instituições de ensino superior públicas ou privadas, a formação inicial e continuada de profissionais do magistério, respeitada a liberdade acadêmica das instituiçôes conveniadas (...)" (Lei n. 11.512/07, art. $2^{\circ}, \$ 2$ ), consolidando a parceria e o reforço às instituiçóes privadas de ensino.

A criação da UAB e a institucionalização do Pró-Licenciaturas como programa preferencial para a formação de professores em exercício marca a adoção de um modelo privilegiado, quase exclusivo, de expansão do ensino superior e de estudos superiores, à distância. As ações de reestruturação e expansão propostas às IFES, pelo REUNI, ainda que possam ser entendidas como esforço de ampliação dos cursos presenciais e aumento do número de vagas, e da diversificação das modalidades de graduação e revisão da estrutura acadêmica, temas suficientemente complexos e polêmicos que não serão enfrentados em curto prazo de tempo.

A expansão dos pólos da UAB se fez a partir do entendimento de que seria a via privilegiada e quase exclusiva para equacionar o problema da formação inicial da juventude egressa do ensino médio, nos cursos de formação de professores - em substituição às atuais licenciaturas e pedagogia. No entanto, o decreto que altera as funções da CAPES restringiu parcialmente essa possibilidade, da modalidade a distância para a formação inicial, ao estabelecer que, na formação inicial, dar-se-á preferência ao ensino presencial, conjugado com o uso de recursos e tecnologias à distância e na formação continuada utilizar-se-ão, especialmente, recursos e tecnologias de educação à distância. 
No encaminhamento da alteração da estrutura da CAPES ao Congresso (PL n. 7.569-D/06), o Ministério justifica o objetivo da proposta, de "institucionalizar programas de formação inicial e continuada, bem como o desenvolvimento de metodologias educacionais inovadoras, visando a qualificação de recursos humanos para a educação básica, mediante os quais será propiciada a efetiva integração entre a educação superior e a educação básica no País, permitindo assim significativa melhoria na qualificação dos docentes do ensino básico" (PL n. 7.568-D, 2006; grifos nossos). O aumento e fortalecimento, junto a diferentes programas, da criação dos mestrados profissionais ${ }^{19}$ são indicadores dos novos contornos que podem adquirir as políticas de formação, articulando a UAB e a CAPES, como nova agência reguladora da formação de professores. A CAPES, juntamente com o FNDE, no financiamento, e o INEP, na avaliação da educação básica, compõe o tripé das agências reguladoras no campo da educação.

Nossa análise é ainda incompleta, diante da inexistência de proposições concretas para a formação de professores, além daquelas divulgadas pela mídia. Assim, arriscamos algumas hipóteses sobre as bases para o desenvolvimento dessas novas formas de regulação da formação dos educadores em nosso país, considerando a situação atual da formação, delineada até o momento, e que procuramos retomar neste artigo.

1. Flexibilização da formação docente, através da institucionalização dos programas emergenciais para formação de professores. A carência de professores no ensino médio orientará a organização de programas de complementação pedagógica "acelerada”, de 120 horas, para as diferentes áreas. Ou, como anunciado pelo atual presidente da CAPES, ${ }^{20}$ a formação emergencial mediante "treinamento" dos 150 mil pós-graduandos para aulas na educação básica.

2. A retomada da proposição dos Institutos Superiores de Educação e das concepções que nortearam sua criação - pela criação dos IFETs e a ampliação dos pólos da UAB -, com a retirada da formação da ambiência universitária, concepção exaustivamente criticada pelas entidades da área, desde a LDB. Nesse sentido, não está descartada a possibilidade de que a formação nas licenciaturas seja 
revisada, à luz das proposições conceituais e metodológicas do programa Pró-Licenciatura, contribuindo para aprofundar a concepção tecnicista e pragmática que vigora nos processos formativos atuais.

3. A reconfiguração da formação inicial em serviço, a distância. A partir da instituição da CAPES como agência reguladora da formação, a educação a distância se implementa como política de Estado para a formação de professores, de forma massiva, para além das iniciativas atuais no âmbito das IES que aderiram ao Pró-Licenciaturas, como resposta à "crise" atual da educação básica e da formação de professores. A criação dos pólos da UAB nos municípios expressa a intencionalidade do Ministério de diferenciar a formação inicial de professores, retirando-a dos centros de educação, faculdades e da ambiência universitária, deslocando-a para os espaços do trabalho - para a educação básica e a escola, nos pólos presenciais nos municípios.

A possibilidade de que esses programas de formação inicial e continuada, ${ }^{21}$ focalizados, pontuais, mediante editais, à semelhança do Pró-Licenciaturas, sejam direcionados aos professores das escolas com "baixo IDEB" não é mera conjetura, diante dos reduzidos recursos orçamentários que impedem a definição de uma política global nacional para a formação continuada de todos os professores. Cria-se também, a partir daí, um nicho mercadológico para o setor privado, principalmente com a grande demanda hoje existente para os cursos de formação continuada e de pós-graduação, comprometendo a construção de uma formação de professores de caráter público.

O objetivo central de transferir para a CAPES a execução das políticas de formação, como anuncia o presidente desta Agência, é implantar um sistema de avaliação dos cursos existentes, nos moldes do que a instituição adota para a pós-graduação, ${ }^{22}$ transpondo, portanto, para os cursos de licenciaturas, os padrôes de excelência da avaliação da pós-graduação. A transposição da lógica da pós-graduação às escolas de educação básica submetem a educação básica e seus profissionais à lógica produtivista que hoje caracteriza a pós-graduação em nosso país. Uma política com esta feição institui a competitividade entre as IES, mediante processos de creditação de instituições formadoras, e ainda a competitividade entre os professores da educação básica, 
pelos cursos de pós-graduação, que não estarão disponíveis a todos os professores, mas aos mais "qualificados".

A transformação dos CEFETs em Universidades e a criação dos IFETs (Decreto n. 6.095/07) podem ser entendidas como fortalecimento da diversificação institucional para a formação de professores para educação profissional-tecnológica, dada a dificuldade de formação no âmbito das atuais licenciaturas nas IEs (Ciavatta, 2006). Mas, introduz uma outra diferenciação, ao prever que os IFETs poderão oferecer cursos de licenciaturas e programas especiais de formação pedagógica com vistas à formação de professores para a educação básica, sobretudo nas áreas de ciências e matemática. Esta proposta é polêmica, exige maior discussão. Os argumentos pautados nos levam a pontuar outras questôes sobre a formação dos professores para a formação profissional tecnológica, hoje não coberta pelas universidades, como a educação superior dos trabalhadores que se dirigem para a educação profissional e a perspectiva de que se formem como profissionais da educação.

Com essas ações, pode-se consolidar a construção de um sistema paralelo de formação de professores para a educação profissional tecnológica, compondo um sistema nacional de formação dos profissionais da educação, mediante a ação reguladora da CAPES.

No complexo processo de regulação dos cursos de formação, cabe nosso olhar atento no sentido de identificar, nas iniciativas que ora se iniciam, em que sentido se desenvolverão os processos de elevação da qualidade da educação básica. Se na direção de criar instrumentos de medida de competências e avaliaçấo do conhecimento de caráter conteudista e instrumental dos professores, acompanhando a centralidade da avaliação nas políticas educacionais e os indicadores do IDEB para a escola pública, ou se, ao contrário, seremos nós a estabelecer, nestas contradições, a contra-regulação, interferindo decididamente nos espaços de definição das políticas de formação, em defesa da escola pública e de novos processos de formação dos educadores, das crianças e jovens em nosso país.

Sem este debate que a área da educação e da formação de professores vem fazendo há 30 anos ou mais, e que o MEC ignora no processo de elaboração do PDE e das políticas de formação, a constituição de novas possibilidades de formação continuará no plano das utopias e de nossas lutas. 
As rupturas necessárias para a formação unitária dos educadores

A impossibilidade de desenvolvimento de uma formação de caráter emancipador, no interior de um sistema profundamente desigual e excludente, nos marcos do capitalismo, nos permite entender e atuar no campo das contradições e evita que possamos cair na armadilha das soluçôes fáceis, ágeis e de "menor custo", que caracterizam, via de regra, as iniciativas no âmbito da educação e particularmente da formação.

Indicar, portanto, a perspectiva da formação sócio-histórica dos educadores situa a formação no campo das suas lutas históricas, no entendimento de que os princípios da base comum nacional unificam a luta contra a degradação da profissão do educador. A formação sóciohistórica e a base comum nacional criam condições para a formação unitária dos educadores, pelo caráter geral, científico e multifacético que essas formulações carregam. Esta concepção supõe uma estrutura institucional que permite viabilizar o conceito de base comum nacional na formação do profissional da educação, proposto pela ANFOPE; não divorcia, na formação do conteúdo específico, o bacharel do licenciado, mantendo o papel dos institutos no processo de formação do educador; e está ligada, em sua construção, a um processo coletivo de fazer e pensar, pressupondo uma construção de experiências particulares (locais e regionais) que, criticadas coletivamente, permitam a construção permanente da base comum nacional. Estas experiências já vêm sendo desenvolvidas em inúmeras IES, que incorporaram à organização curricular dos cursos de formação, os princípios da base comum nacional. ${ }^{23}$

Assim, a defesa de uma política global de formação do profissional da educação, de caráter sócio-histórico e que responda às necessidades atuais, implica:

1) Uma ação conjunta entre as universidades e demais instâncias formadoras e os sistemas de ensino, de maneira a rever a formação básica, assegurar condições dignas de trabalho e formação continuada;

2) a revisão das estruturas das instituiçōes formadoras do profissional da educação, experienciando novas maneiras de organizar a formação do educador e avançando para formas de organização 
por cursos e programas, para todos os níveis de ensino, contemplando a formação inicial e continuada;

3) o estabelecimento de uma integração permanente entre as instituições de formação do profissional da educação, as entidades organizadas dos trabalhadores da educação e demais entidades da área educacional, na instituição e fortalecimento de fóruns coletivos de debate e indicação de políticas de formação e valorização profissional.

Nessa perspectiva, destacamos a relevância desta formulação no contexto das alterações que vêm se produzindo no interior das IES, de retirada dos estudos relativos aos fundamentos das Ciências da Educação e da teoria pedagógica, dos cursos de formação de professores. A formação de base científica e técnica, em condições de igualdade para todos, é condição para forjar uma nova qualidade da formação dos educadores, que não se reduz a "treinamento", para lidar com os complexos processos na formação da infância e da juventude. Por esse motivo, uma política promissora para a formação inicial e continuada dos educadores deve fundar-se em outras condições, que permitam a participação ativa dos professores e de suas entidades nos processos de definição de sua formação e nos rumos da educação pública em nosso país.

Uma política de formação de professores exige que sejam tratadas, igualmente, as bases da educação escolar, visando sua transformação para a construção de uma nova qualidade da educação básica, orientada pelas necessidades sociais da formação de nossa infância e da juventude.

Nesse sentido, a construção de diretrizes que induzam os estados e municípios à essa transformação ultrapassa aquelas definidas no Compromisso Todos pela Educação, do Plano de Desenvolvimento da Educação. ${ }^{24}$ Supõe outros interlocutores, os educadores, os estudantes, os pais, e os movimentos sociais, alijados do processo de construção das políticas atuais e do novo Plano de Desenvolvimento da Educação. Além da exigência do financiamento necessário, indicado pelos pesquisadores e estudiosos da área, os educadores também têm indicado outras ações urgentes para uma nova qualidade da escola e da educação básica, sem o que não se poderá vislumbrar uma nova educação: a capacidade de romper com a fragmentação disciplinar e avançar para outras formas de trabalho com as crianças, na direção da unidade 
metodológica, do trabalho coletivo e interdisciplinar; as condições de auto-organização dos estudantes na gestão democrática da escola; a participação dos pais, da comunidade e dos movimentos sociais na vida da escola; a democratização das funções diretivas escolares; a implementação da escola integral; a redução do número de alunos por sala na educação básica; reorganização dos currículos, atendendo às necessidades sociais e acompanhando o avanço técnico-científico contemporâneo; o estudo e a avaliação das experiências de organização da escola por ciclos de formação, trazendo para o debate professores, funcionários, pais e comunidade, são condições essenciais para que as instituições formadoras construam também processos formativos, à luz de uma nova concepção de escola e de educação que tenha como futuro um projeto social emancipador.

Por último, cumpre destacar que a análise da realidade da escola, em suas relações com a sociedade, bem como a reflexão sobre as condições para o pleno desenvolvimento do trabalho educativo e pedagógico, se sobrepõe às atuais determinações colocadas pelas políticas de melhoria da qualidade da escola pública, centradas unicamente na avaliação do rendimento dos alunos, como o IDEB. Neste processo, o estudo das concepções, fins e objetivos, conteúdos, metodologias e práticas da educação, diante dos novos desafios para a organização dos tempos e espaços da escola e do trabalho pedagógico com os alunos, ganha centralidade.

Criar estas condiçôes requer processos de ruptura com as políticas atuais em várias direções:

a) a revisão total da $L D B$ e de seu arcabouço legal, em especial as diretrizes de formação de professores, assumindo e instituindo a responsabilidade acadêmica das faculdades e centros de educação das IES, na formação dos educadores;

b) firmar a centralidade dos estudos no campo das Ciências da Educação e das teorias pedagógicas, nos processos formativos em desenvolvimento, na formação inicial, nos cursos de nível médio, na graduação, licenciaturas plenas e na formação continuada dos educadores, organicamente articulados e incorporando os princípios da base comum nacional nos cursos de formação;

c) Estabelecimento de comissões próprias para os processos de criação, credenciamento e reconhecimento dos cursos de formação 
dos profissionais da educação, com a participação das entidades científicas e acadêmicas da área.

d) aprovação das diretrizes da carreira do magistério, prevendo jornada única em uma escola, jornada integral e dedicação exclusiva, instituição do piso salarial, prevendo metas de proporção de $50 \%$ de horas com atividades em aulas e $50 \%$ às demais atividades, com tempo para o estudo, para a investigação, análise e interpretação de seu trabalho, estabelecendo também políticas de formação integral pelo acesso à leitura, à literatura, às artes, ao esporte, à organização sindical e política;

e) transformação dos atuais pólos da UAB em Centros de Formação de Professores, articulados à Rede de Nacional de Formação Continuada de Professores, geridos pelos educadores e apoiados pela universidade - com a participação ativa das unidades das Ciências da Educação: faculdades/centros de educação - e pelos sistemas de ensino, instituídos como espaços de produção coletiva dos educadores, de novos conhecimentos sobre a escola, a sala de aula e os processos formativos, novas metodologias de ensino e de trabalho pedagógico.

\section{Em tempo...}

Os embates entre projetos diferenciados de formação, marcados por interesses contraditórios, não se encerram e vão evidenciando as contradições no processo de definição e de implementação das políticas. Os desafios para os setores progressistas aumentam, na medida em que os "interlocutores válidos", escolhidos nessa caminhada, não são os sujeitos do processo educativo, aqueles que, nas escolas e nas universidades, deveriam ser partícipes ativos na construção das políticas educacionais que constroem ou destroem as suas vidas: os professores, os estudantes, os educadores da escola e os pais. As continuidades que se estabelecem entre governo e esferas da sociedade civil, para a construção do PDE, sinalizam nova configuração aos processos de gestão da educação e da escola, ao ensino e ao trabalho docente, que merece ser examinada a muitas, muitas mãos.

Experiências institucionalizadas com o Programa Mais Educação do PDE já vêm sendo desenvolvidas no âmbito do trabalho pedagógico 
A (nova) política de formação de professores: a prioridade postergada

da escola, com a ação de educadores sociais e ONGs, e têm como foco a melhoria do rendimento do aluno e do aproveitamento do tempo escolar, visando reduzir evasão, reprovação e distorçôes de idade-série. Estas experiências, em dimensóes que se constituem próprias do trabalho docente, expandem a docência para os educadores sociais, evidenciando rupturas com os princípios históricos do movimento dos educadores em relação ao trabalho docente e à própria concepção de escola integral. Com isso, contribuem para construir, no presente, uma educação reduzida ao seu caráter meramente instrutivo, uma escola com função "contenedora" (Tiramonti, 2005) de crianças e jovens em situação de risco e, como futuro, o aprofundamento dos processos de submissão e exclusão que acompanham políticas regressivas na educação.

Outra particularidade nas políticas atuais é a iniciativa de estabelecer premiação dos professores pelo desempenho dos estudantes nas provas nacionais, que não é nova em nosso país, ${ }^{25}$ mas passa a ser validada pelas ações do PDE, como vem sendo anunciado pela Secretária de Educação do governo do estado de São Paulo, ${ }^{26}$ e, pela via da premiação, pretendem maior controle sobre os professores e sobre os processos de trabalho docente, visando sua adequação às exigências demandadas pelos descritores e matrizes de referência das provas e exames nacionais. ${ }^{27}$ Contraditoriamente, preparam os estudantes e professores para as "provas" e a avaliação. Desta forma restrita, assumem a lógica produtivista e mercadológica que se impõe à educação, uma "pedagogia de resultados", no dizer de Saviani (2007), que se guia, nas atuais circunstâncias, pelos mecanismos das chamadas "pedagogia das competências" e da "qualidade total".

A ênfase no caráter meritocrático, hierárquico, subordinado e tutorial do trabalho docente está presente no $\mathrm{PDE},{ }^{28}$ será reforçada pelas ações hierárquicas e centralizadas dos sistemas sobre os professores, visando atingir os índices de qualidade pré-determinados. Aliadas aos processos implementados de avaliação da educação básica, estas ações permitirão o desenvolvimento de uma "nova face" da gestão da descentralização (Oliveira, 2004) e dos processos de gestão da escola e do trabalho: a proposição de que a escola conte com maior "responsabilidade" nos processos de seleção, condições de trabalho e desenvolvimento dos professores, como vem sendo proposto em estudos da OCDE (2005) aos países europeus. 
Sejam quais forem as "saídas", elas certamente não virão na direção que os setores progressistas almejam, sem luta e resistência, na direção de construir processos de formação com qualidade elevada, fundados na concepção sócio-histórica do educador.

Políticas de melhoria da escola centradas essencialmente na avaliação do rendimento dos alunos e em sua publicização para os pais (...) tendem fortemente para o lado da pressão e dos estímulos ao rendimento (...) não confiam muito em professores reflexivos. (...) essas abordagens não exigem um docente profissional e até mesmo preferem um docente que domine e execute os métodos e as técnicas reputados eficazes e comprovados. (Lessard, 2006, p. 231, grifo nosso)

Será esta a nova tarefa da CAPES como agência reguladora da formação de professores? Que concepções a informarão? Como se exercerá a regulação da formação? Estará restrita aos cursos e instituições formadoras ou se expandirá para o trabalho docente?

A retomada das discussões sobre os fins da educação, trazendo para o centro do debate a questão dos projetos históricos e de sociedade que queremos, não está posta pelo novo governo e pelo Ministério, orientado e marcado pelas soluçôes "de resultado" que impregnam as políticas de avaliação da educação básica atuais, impeditivas de um referencial para projetar a formação dos profissionais da educação sobre bases mais elevadas, para lidar com a formação atual das novas geraçôes, e a construção de uma nova vida, uma nova humanidade.

A construção de novos processos formativos, que respondam às exigências e necessidades sociais na atualidade, se situa no campo das contradiçóes e das lutas pelo anúncio de uma outra sociedade, justa e igualitária, de progresso e emancipação. É o que nos move nestas circunstâncias.

Recebido e aprovado em agosto de 2007.

\section{Notas}

1. О рів brasileiro, em 2006, foi de 2 trilhões e 322 bilhões de reais. Isso significa que, levando-se em conta a informação do próprio MEC de que o Brasil gasta em educação, atualmente, 4,3\% do PIB, os recursos para 2007 deveriam ser da ordem de 99 bilhões e 846 milhōes de reais (...) e o montante a ser destinado à educação básica seria de 76 bilhōes e 800 milhōes, muito superior, portanto, ao valor de 43 bilhōes e 100 milhões

Educ. Soc., Campinas, vol. 28, n. 100 - Especial, p. 1203-1230, out. 2007

Disponível em <http://www.cedes.unicamp.br> 
mencionado no quadro do MEC (Saviani, 2007). Segundo dados da CNTE, o Brasil deve, hoje, mais de $\mathrm{R} \$ 540$ bilhóes e precisaria de $\mathrm{R} \$ 180$ bilhóes (10\% PIB, proposta do PNE da Sociedade Brasileira, de 98) para oferecer um ensino público de qualidade e gratuito em todas as etapas do aprendizado (Boletim CNTE, abr. 2007).

2. Cf. Pochmann (2007).

3. Informações disponíveis em: <www.cnte.org.br>. Acesso em: 10 ago. 2007.

4. Cf. Manifestação da ANFOPE ao Programa. Disponível em: <www.lite.fae.unicamp.br/anfope>

5. A destinação orçamentária, neste ano, será de $\mathrm{R} \$ 3$ milhōes. Informaçôes disponíveis em: <www.mec.gov.br>. Acesso em: 27 jul. 2007.

6. Programa do MEC, em parceria com o $\mathrm{MCT}$, destinará $\mathrm{R} \$ 75$ milhóes para apoiar a produção de conteúdos educacionais digitais multimídia para o enriquecimento curricular e o aprimoramento da prática docente, incentivar produçōes nas áreas das ciências e tecnologias, voltadas ao ensino médio, e fomentar o mercado. Cf. Portal MEC. Disponível em: <www.mec.gov.br>. Acesso em: 27 jul. 2007.

7. Este número de estudantes contrasta com a carência apontada pelo CNE, no Relatório Escassez de Professores no Ensino Médio. Propostas estruturais e emergenciais (CNE, 2007), de aproximadamente 250 mil professores para as mais diversas áreas.

8. Gusso (2007) apresenta, na linha do tempo da formação de professores, dados que mostram as condiçôes de formação desde 1930. De forma interessante, destrói o mito da excelência da formação de normalistas nos anos de 1960. Na década de 1950-60, formaram-se 60 mil normalistas. De cada 100, menos de 25 abraçam a docência. Professores leigos são contratados para dar aulas.

9. O Parecer CNE/CP n. 05/06, que estabeleceu programas de complementação pedagógica de 800 horas, revogando a Resolução n. 02/97, encontra-se no CNE, sem homologaçãa, no entendimento do Ministério de que essa carga horária deva ser rebaixada para 120 horas.

10. Segundo manifestação do presidente da CAPES, "existem 150 mil alunos de pós-graduação no Brasil que podem trabalhar pela melhoria da qualidade da formação (...)". Disponível em: <www.revistaeducacao.uol.com.br> Acesso em: 15 ago. 2007.

11. Cf. Banco Mundial, Higher Education: the lessons of experience (1994). As implicaçôes desta organização do ensino superior foram exaustivamente denunciadas nos últimos anos tanto pelas entidades educacionais, quanto por estudiosos da área (Cf. Catani \& Dourado, 2000). Ver, especialmente, Educação \&Sociedade, n. 68 e 80.

12. O censo realizado pelo Ministério em 2001 mostrava que havia 306 cursos na época, 239 deles em instituiçôes públicas e o restante, em particulares. No ano 2000, havia apenas 110 cursos no país. Em 2006, o número de cursos normais superiores chegou a 702, sendo 490 em instituiçôes privadas e filantrópicas e 208 em instituições públicas. Quanto aos Cursos de Pedagogia, existe hoje um total de 1.438 cursos: 657 em instituições públicas e 780 em instituiçóes privadas e filantrópicas, sem considerar os inúmeros ISEs e cursos de licenciaturas criados também nesse período.

13. Em vários pólos, a presença dos estudantes é demandada uma vez por semana, unicamente, para o trabalho de tutoria. A presença em outros momentos é optativa, e na avaliação da aprendizagem, mediante "provas", obrigatória.

14. Programas especiais presenciais foram criados em várias universidades públicas articulados aos sistemas de ensino. Estes programas incorporaram os especialistas das redes públicas - supervisores, orientadores pedagógicos, coordenadores - nas funções de tutores/ 
mediadores/professores dos cursos especiais de formação de professores das séries iniciais em exercício. Ver, mais especificamente, PROESF, na UNICAMP, e PIE na UNB. Com isso, criaram as condições para que se produzisse a concepção, hoje talvez inconscientemente adotada pelas universidades, de que os sistemas de ensino podem se responsabilizar pela formação inicial de seus professores, com o envolvimento de seus "especialistas" que são, antes de tudo, professores. Com isso, reforçam o movimento de retirada das universidades da formação de professores que observamos em vários países, desde o início da década de 1990, como nos referimos anteriormente.

15. Para uma análise inicial da concepção deste Programa, ver Freitas (2003).

16. Iniciado em 2005, curso em nível médio normal, modalidade a distância, destinado à professores em exercício na educação infantil, atinge hoje 2.877 professores de $191 \mathrm{mu}$ nicípios brasileiros em 6 estados.

17. Cerca de 184 mil funçôes docentes dos anos/séries finais do ensino fundamental e 56 mil funções no ensino médio da rede pública em todo o país são ocupadas por profissionais sem a formação legal exigida para a função. A área de atuação do Pró-Licenciatura é o resultado da soma dos níveis de escolaridade: médio, com ou sem magistério, e do superior sem licenciatura, que equivale a $26,21 \%$ do total das funçóes docentes no Brasil. Cf. $<$ www.mec.gov.br/seb >.

18. Tal como no Pró-Licenciatura, a CAPES vai publicar editais para que as instituiçôes interessadas desenvolvam programas de formação docente segundo referenciais definidos pela instituição. Cf. matéria disponível em: <www.revistaeducacao.com.br>, ago. 2007. Acesso em: 15 ago. 2007.

19. Dados recentes sobre novos cursos de pós-graduação indicam a aprovação de 13 cursos na subárea multidisciplinar ensino de ciências e matemática, dos quais 10 são mestrados profissionais, 02 mestrados acadêmicos e 01 doutorado acadêmico. Na subárea educação foram aprovados 05 cursos (CAPES, 2007).

20. Cf. Entrevista do presidente da CAPES a Revista Educação, onde afirma: "Existem 150 mil alunos de pós-graduação no Brasil que podem trabalhar pela melhoria da qualidade da formação (...)". A CAPES pretende criar mecanismos para estimular - inclusive por meio de remuneração - esses estudantes a atuar como docentes de escolas públicas, após passarem por treinamento. Cf. <www.revistaeducacao.com.br>. Acesso em: 15 ago. 2007.

21. Ver matéria da nota 20.

22. Ver matéria da nota 20.

23. Nos documentos finais dos Encontros Nacionais da ANFOPE, podem ser encontrados os estudos e as proposições históricas da entidade relativos à base comum nacional.

24. Cf. Diretrizes do Compromisso Todos pela Educação (PDE/MEC, 2007). Disponível em: $<$ www.mec.gov.br>.

25. Em 2000, em Fortaleza, os resultados de processo de avaliação de 5 mil crianças defasadas na $4^{a}$ Série permitiram que os professores recebessem um "plus" em remuneração, por aluno com nota 7 em cada uma das disciplinas avaliadas. No estado da Bahia, o governo do período de 2002-2006 implementou processos de avaliação visando a certificação docente.

26. Cf. Matéria "Nova Secretária quer premiar professores por desempenho", na qual a nova secretária de Educação do Estado de São Paulo defende "que os docentes devem receber um dinheiro extra segundo o desempenho de suas turmas em exames de verificação de aprendizagem dos alunos, como SAEB, Prova Brasil (ambos federais) e SARESP (estadual)". Cf. Folha On-line, 25 jul. 2007. Disponível em: <http://notícias.uol.com.br/educacao>.

Educ. Soc., Campinas, vol. 28, n. 100 - Especial, p. 1203-1230, out. 2007

Disponível em <http://www.cedes.unicamp.br> 
A (nova) política de formação de professores: a prioridade postergada

27. Cf. site do MEC: "Prova Brasil e SAEB: O que cai na prova? Conheça os tópicos e descritores". Disponível em: <www.mec.gov.br>. Acesso em: ago. 2007.

28. Cf. Diretrizes do Compromisso Todos pela Educação, Programa "Conteúdos Educacionais" do PDE. Disponível em: < www.mec.gov.br>.

\section{Referências bibliográficas}

AGUIAR, M.A. et al. Diretrizes curriculares do Curso de Pedagogia no Brasil. Educação \& Sociedade, Campinas, v. 27, n. 96, p. 819-842, Especial - out. 2006.

ANFOPE. Documentos Finais dos VI, VII, VIII e IX e X Encontros Nacionais da Associação Nacional pela Formação dos Profissionais da Educação, 1992, 1994, 1996 e 1998 e 2000.

ANFOPE. Manifestação ao CNE Escola de 9 anos, em 2006.

ARAUJO, I. Textos, contextos e intertextos do trabalho pedagógico do professor mediador do curso PIE-FE-UNB. 2007. Tese (Doutorado) - Universidade Estadual de Campinas, Campinas.

BARROSO, J. O Estado, a educação e a regulação das políticas públicas. Educação \& Sociedade, v. 26, n. 92, p. 725-751, Especial out. 2005.

BRASIL. Pró-docência Programa de Consolidação das Licenciaturas. Brasília, DF: MEC; SESU; DEPEM, abr. 2007a.

BRASIL. Plano de Desenvolvimento da Educação. Brasília, DF: MEC, 2007b.

CAMPOS, R. Cenário da formação de professores no Brasil. Campinas, ANFOPE. Disponível em: <www.lite.fae.unicamp.br/anfope>

CAPES/MEC. Informativo eletrônico, n. 92, 27 jul. 2007.

CATANI, A.M.; OLIVEIRA, J.F.; DOURADO, L.F. Mudanças no mundo do trabalho e reforma curricular dos cursos de graduação no Brasil. XXIII Reunião Anual da ANPEd, Caxambu, MG, 2000.

CIAVATTA, M. Os Centros Federais de Educação Tecnológica e o ensino superior. Educą̧āo \& Sociedade, Campinas, v. 27, n. 96, p. 911934, Especial - out. 2006.

1228 Educ. Soc., Campinas, vol. 28, n. 100 - Especial, p. 1203-1230, out. 2007 
CNTE. Retrato da Escola 1, 2 e 3. Disponível em: <www.cnte.org.br>. 2000, 2001 e 2002.

CNTE. Posição da CNTE sobre o PDE. Brasília, DF, 2007.

CHUEIRE, C. A formação superior de professores através de midias interativas. 2005. Tese (Doutorado) - Universidade Estadual de Campinas, Campinas.

DIAS, R.E.; LOPES, A.C. Competências na formação de professores no Brasil: o que (não) há de novo. Educação \& Sociedade, Campinas, v. 24, n. 85, p. 1155-1177, dez. 2003.

FREITAS, H.C.L. Certificação docente e formação do educador: regulação e desprofissionalização. Educação \& Sociedade, Campinas, v. 24, n. 85, p. 1095-1124, dez. 2003.

GUSSO, D.A. Professores leigos são contratados para dar aulas. Nova Escola, São Paulo, no 204, p. 62, ago. 2007.

INTERNACIONAL DA EDUCAÇÃO. Carta de Manágua, 2007.

LESSARD, C. A universidade e a formação profissional dos docentes: novos questionamentos. Educação \& Sociedade, v. 27, n. 94, p. 223240, jan.-abr. 2006.

MARQUES, C.A.; PEREIRA, J.E.D. Fóruns de licenciaturas em universidades brasileiras. Educação \& Sociedade, Campinas, ano 23, n. 78, p. 117-142, abr. 2002.

MIZALA, A.; ROMAGUERA, P. Sistemas de incentivos en educación y la experiência del SNED em Chile. Centro de Economia Aplicada, Departamento de Ingeniería Industrial, Universidad de Chile. Texto ao Seminário Desenvolvimento Profissional de Professores, MEC/InEP, Brasil, 1999. (mimeo.).

MORDUCHOWICZ, A. Carreras, incentivos y estructuras salariales docentes. PREAL, Buenos Aires, n. 23, 2002.

OECD. La cuestión del profesorado: atraer, capacitar y conservar a profesores eficientes. França, OECD, 2005. Disponível em: <http:// www.oecd.org/edu/teacherpolicy>. 
A (nova) política de formação de professores: a prioridade postergada

OLIVEIRA, D.A. A reestruturação do trabalho docente. Precarização e flexibilização. Educação \& Sociedade, Campinas, v. 25, n. 89, p. 1127-1144, set.-dez. 2004.

POCHMANN, M. Tendências e debates. Folha de S. Paulo, São Paulo, 12 mar. 2007.

POWER, S.; WHITTY, G. Mercados educacionais e a comunidade. Educação \& Sociedade, Campinas, v. 24, n. 84, p. 791-815, set. 2003.

PREAL. Seminário Internacional Sobre Desempenho de Professores na América Latina e Caribe. Reportagem de Gisele Pinto, recebida pela rede, em agosto de 2002, "Seminário Internacional traça estratégias para a melhoria na formação de educadores”. Brasília, DF, 2002.

SAVIANI, D. O ensino de resultados. Caderno Mais, Folha de S. Paulo, 29 abr. 2007.

SEEB/SEED/MEC. Programa de Formação Inicial para Professores em Exercício no Ensino Fundamental e no Ensino Médio. Pró-Licenciatura, Brasília, DF, 2005.

TIRAMONTI, G. La escuela en la encrucijada del cambio epocal. Educação \& Sociedade, v. 26, n. 92, p. 889-910, Especial - out. 2005.

TORRES, R.M. Melhorar a qualidade da educação básica? As estratégias do Banco Mundial. In: De Tommasi, L.; Warde, M.J.; Haddad, S. (Org.). O Banco Mundial e as políticas educacionais. São Paulo: Cortez, 1996.

VAILLANT, D. Construcción de la profesión docente en América Latina. Tendencias, temas y debates, PREAL, 2004.

WEBER, S. Profissionalização docente e políticas públicas no Brasil. Educação \& Sociedade, Campinas, v. 24, n. 85, p. 1125-1154, dez. 2003. 